\title{
GENOTYPE DISCRIMINATION: THE COMPLEX CASE FOR SOME LEGISLATIVE PROTECTION
}

\author{
HENRYT. GREELY ${ }^{\dagger}$
}

\section{INTRODUCTION}

Substance and process, process and substance. They dance through law; they dance through life. The big news from the dueling publications of "the" human genome was that humans have only about one-third more genes than round worms; we share versions of about ninety-nine percent of our genes with mice. The substance of the genes is important to the creature they produce, but so is when those genes are turned on, how high, and for how long. In genomes, the expression is as important as what is expressed. The substance of legislation is important; so is the process-the public discussions, debates, and understandings-through which it is made and implemented. The federal government should prohibit some uses of genetic information in decisions by employers and health insurers, but how those prohibitions are argued and implemented may be more important than the fact of their adoption.

This piece begins, in Part $\mathrm{I}$, by demonstrating that genetic discrimination is not likely to have serious effects on a substantial number of people. It then points out, in Part II, weaknesses in both many of the justifications for legislation banning genetic discrimination and many of the methods suggested for doing so. It ends, with Part III, by supporting carefully crafted, and narrowly argued, federal legislation limiting genotype discrimination. There is a good case for such laws, but there just is not a case that is both good and simple. And to argue the case without using the shades of gray, to debate point by (counter) point, can do more harm than good.

\section{THE LIMIITED REALITY OF GENETIC DISCRIMINATION}

Genetic discrimination is a much greater threat in people's fears than it is in reality, today or in the foreseeable future, for both scientific and social reasons. Most of the discussion that follows 
concerns the science behind fears of human genetics; I have tried to make it easily understandable to legal audiences. An accurate understanding of the power, and the limits, of genetic prediction is crucial to a useful analysis of genetic discrimination.

\section{A. Genes and Disease}

Start with some definitions. People do not have "genes" for disease. As far as we know, all humans have the same set of genes, about 32,000 of them,' except for those few genes on the $Y$ chromosome, found in men and not in women. ${ }^{2}$ Those genes come in many variations; indeed, for the most part, the human genes are just human variations of genes found in other primates, mammals, animals, or broader sets of life forms. Any two humans, on average, will be identical in their DNA sequences $99.9 \%$ of the time and $99.99 \%$ of the time in the regions of genes that contain the genetic code for constructing proteins (the so-called exons). The few differences make up genetic variations or different "alleles" of the genes. Traits or diseases are considered "genetic" when a person with a particular allele has a much greater chance than average of having a particular trait or disease-more broadly, when the genotype is correlated with a particular "phenotype."

Progress in human genetics has led to fears about genetic discrimination, particularly in insurance and employment, because of the perceived power of human genetics to make predictions about people's future lives-and hence future health insurance risks, time of death, and employment productivity. The popular vision of a genetic disease is something that is caused only by a particular allele, that cannot be avoided by a person with that allele, that cannot be treated, and that leads to an inevitable death. And, indeed, sometimes human genetics can lead to predictions about people that are powerful, both because they are highly likely to come true and because they would have substantial consequences on those persons' lives.

Huntington disease, ${ }^{3}$ a neurodegenerative disorder, may be the

1 This is far fewer than many scientists expected. Elizabeth Pennisi, The Human Genome, 291 SCIENCE 1177, 1178 (2001).

2 There are also some conditions caused by having too many or too few copies of genes. Down syndrome, which is caused by having an extra copy of Chromosome 21 and which involves mental retardation along with a variety of physical ailments, is an example. It is not clear whether these kinds of conditions are usually included in the term "genetic."

Even the names of some genetic (and nongenetic) diseases are controversial. In 
paradigm for this kind of genetic condition. It is only the product of a genetic variation. As far as we know, the only way to get Huntington disease is to have an excessive number of repeats of three bases of DNA-cytosine, adenine, and guanine, or CAG-in a particular stretch of a gene found near the end of the short arm of Chromosome 4. Most people have 10 to 20 repeated CAGs; only people with 36 or more ever develop Huntington disease. No one with more than 38 repeats is known to have avoided the disease, except by dying first from something else. There is no significant treatment for Huntington disease; death follows inevitably after about fifteen years of progressive physical and mental disability. ${ }^{*}$ Many childhood genetic diseases, like Tay-Sachs disease, are similarly implacable.

But Huntington disease and other certain and inevitable links between genetic variations and disease are proving to be the exceptions, not the rule. In some genetic diseases, the physiological defect may follow inevitably from the genetic variation, but disease and death may not. For example, phenylketonuria ("PKU"), a genetic disorder affecting about one birth in 10,000 , is caused by the inability to metabolize the essential amino acid phenylalanine. This leads to the build up of excessive amounts of phenylalanine, which then causes mental retardation. If a child is known from an early age to have PKU, however, an arduous diet, low in phenylalanine, prevents retardation so effectively that PKU screening at birth is now required in all U.S. states." Even some of the more common genetic diseasescystic fibrosis, sickle-cell anemia, and beta thalassemia-although not curable, are now susceptible to treatments that have expanded the quantity and improved the quality of the lives of those born with defective versions of the responsible genes.

Even more importantly, many alleles associated with nonrare diseases, particularly common diseases, increase the bearer's risk-but

recent years authors and journals have split over making disease names possessiveHuntington's disease- or not-Huntington disease. This Article will follow Occam's Rizor (Occam Razor?) and omit the possessive form.

'Even in Huntington disease, the age of onset varies for reasons that are not clear. Most people are diagnosed in their thirties through fifties, but some are diagnosed much earlier and a few much later. There is some correlation between a greater number of repeats and earlier onset, but it is not perfect.

"Phenylketonuria and its associated diet leave a trace that the rest of us encounter. The Food and Drug Administration has required that all packages containing the artificial sweetener aspartame (known commercially as Nutrasweet) must contain a warning that the product contains phenylalanine. The next time you have a diet soft drink, look on the label for "Warning: Phenylketonurics. This product contains phenylalanine." 
not all the way. Having one copy of disease-related alleles of either of the genes BRCA 1 and BRCA 2 increase a woman's chances of being diagnosed with breast or ovarian cancer. Her lifetime risk of breast cancer increases from roughly $10 \%$ to somewhere between $50 \%$ and $85 \%$. Her risk of ovarian cancer rises from about $1 \%$ to about $30 \%$. (These ratios, the percentage of those with a given genotype who develop a particular phenotype, are known as the genotype's "penetrance.") No one knows yet what determines which women with these mutated alleles get the disease-variations in other genes, environmental influences, or just bad luck. It is clear, though, that not all women with these alleles get either disease; most women with the alleles do not get ovarian cancer.

There clearly are genetic variations, still largely unknown, that are associated with higher (and lower) risk of asthma, diabetes, coronary artery disease, stroke, schizophrenia, and a host of other common diseases. But, for the most part, the change in risk associated with any given allele seems likely to be quite small. This should not be surprising. The strong associations between genetic variations and disease-the alleles with a high penetrance-are the easy ones to find. A gene for asthma with the near-perfect penetrance of Huntington disease, or even the penetrance of BRCA 1, would stand out in family studies and would be easy to find. More genetic links to common diseases are probably proving hard to find because they are not very powerful.

For common diseases, the genetic story is likely to be extremely complicated. Alzheimer disease provides a useful example. An American has about a $10-15 \%$ chance of being diagnosed with Alzheimer disease, usually after the age of sixty-five." Three genespresenilin 1, presenilin 2, and the amyloid precursor protein genehave now been found where unusual alleles lead almost certainly to the disease, and usually several decades earlier than usual. Mutations in presenilin 1 may be found in as many as 1 person in 1000; the other two alleles are vanishingly rare. Altogether, they may account for about $1 \%$ of the people who get Alzheimer disease.

Another gene, APOE, is also associated with Alzheimer disease. Everyone has two copies of the APOE gene, one inherited from each parent. This gene has three common alleles, called APOE 2, APOE 3,

${ }^{6}$ The precise risk is not known in part because of uncertainty over the diagnosis, and hence the incidence, of Alzheimer disease. It is very difficult to distinguish between Alzheimer disease and other forms of dementia in the elderly; the only definitive method is through autopsies, which often are not performed. 
and APOE 4. ${ }^{7}$ The APOE 3 allele is the most common, making up about $70 \%$ of all the versions found. People who inherit two copies of the APOE 4 allele-about $2 \%$ of the population-have a very high risk of getting Alzheimer disease, although at the usual age. People with one copy of the APOE 4 allele and one copy of either APOE 3 or APOE 2 make up about $15 \%$ of the population. Their risk of Alzheimer disease is somewhere between $30 \%$ and $50 \%, 2$ to 5 times higher than the general population risk. But someone with one APOE 4 allele is still less likely to be diagnosed with Alzheimer disease than to be diagnosed with it. On the other hand, a person with two APOE 2 alleles, about $1 \%$ of the population, has a very low chance of being diagnosed with Alzheimer disease.

Thus, the same disease is strongly genetic for about $2 \%$ of the population, weakly genetic for about $15 \%$ of the population, and, genetically, nearly ruled out for about $1 \%$ of the population. The other $7 / 8$ of the population, which will account for most people with Alzheimer disease, have, as far as we now know, risks that are neither increased nor decreased significantly by their genes. While other alleles of other genes are under investigation for association with Alzheimer disease, the logic of the discovery process means that the strong associations are likely to be rare; the less-rare associations are likely to be weak.

The relationship between genetic variations and disease is thus complicated. For some few, unlucky people, possession of a particular allele is a very strong predictor of disease, which may or may not be treatable. Most people, though, are likely to have much less powerful genetically predicted disease risks. For example, my particular genetic variations might make my risk of adult onset diabetes $8 \%$ instead of $5 \%$, but my risk of coronary artery disease $12 \%$ instead of $15 \%$. The genetic discoveries that lie ahead most likely will have relatively small effects on someone's predicted risk of a disease. ${ }^{8}$ The implications for the risk of genetic discrimination are obvious.

\section{B. Genes and Society}

Whether the health risks predicted by genetic variations are big or

"APOE 1, the first version to be found, was strongly associated with a cholesterolrelated disease. It turned out to be quite rare.

And, of course, if there turns out to be a useful intervention to prevent the disease from occurring in people with the genetic risk, preventive measures developed from knowledge of the genotype might actually decrease the tested person's risk. 
small, they can lead to genetic discrimination only if those risks are taken into consideration in making decisions. Concern about genetic discrimination in the United States has focused on health coverage and employment. Structural reasons exist, though, that limit the extent to which genetic risks will be taken into consideration in those areas.

Start with health care. Note first that genetic discrimination in health insurance is almost exclusively an American problem; the United States is unique among wealthy nations in not guaranteeing health coverage to nearly all of its citizens, regardless of either medical or financial status. In the hoped-for event that the United States joins the rest of the rich world by guaranteeing its residents health coverage, genetic discrimination in health insurance will be largely moot. ${ }^{9}$ But the structure of the current U.S. health care financing system, for all its many flaws, exposes only a few people to the risk of genetic discrimination.

Genetic information that leads to conclusions about a person's likely future health care costs can directly affect whether that person gets health coverage only if the insurer can decline to provide that coverage because of those higher risks, a practice known as "medical underwriting." The vast majority of Americans do not have medically" underwritten health coverage; they are covered without regard to their future health risks. Nearly 40 million Americans are covered through the federal Medicare program with no medical underwriting. Another roughly 30 million poor Americans are covered by the statefederal Medicaid program, again with no medical underwriting. About 140 to 150 million Americans are covered through employersusually their own, their spouses', or their parents'. The KassebaumKennedy Act of 1996, also known as HIPAA, bars almost every employer that provides health coverage from using medical information to pick and choose whom to cover among eligible employees and their dependents. ${ }^{10}$ About 45 million Americans have no health insurance, almost always because they either cannot afford to purchase it independently or do not choose to do so.

${ }^{9}$ It would, most likely, continue to be possible for people to buy health insurance to supplement their guaranteed coverage, as in Canada, or to buy private insurance instead of the government-guaranteed coverage, as in the United Kingdom or Germany. As long as the basic, government-guaranteed coverage is adequate, neither alternative raises serious concerns.

${ }^{10}$ Health Insurance Portability and Accountability Act of 1996, Pub. L. No. 104192, 110 Stat. 1936. 
So who could be victims of genetic discrimination in health coverage? Only people who purchase individually underwritten health coverage or who would purchase it if it were not made either entirely unavailable or exorbitantly expensive because of medical underwriting. There is no exact count of how many people fall into either of those categories; my best guess is about 10 to 20 million. Whatever the actual total, it is a substantial number, but well under $10 \%$ of the U.S. population." One's lifetime chance of needing, at some point, to purchase medically underwritten coverage is higher than the current percentage of people in that situation, but, most likely, it will remain low.

The conclusion that genetic discrimination in health coverage threatens few people may be a surprising one, but it is consistent with most of the available evidence. There have been a few studies that have purported to find such genetic discrimination. They generally have relied on unexamined reports from people who said they had been discriminated against and on the second-hand reports of genetic counselors who had been told that this had occurred. The shortage of clear, well-documented examples of genetic discrimination in health insurance is noteworthy. So is the fact that health insurers have not announced that they would underwrite for genetic-related disease risks. One careful study, in fact, found that insurance agents, the most important source for medically underwritten coverage, go out of their way to avoid disqualifying people because of genetic risks." In more than forty states some form of genetic discrimination by health insurers is illegal; in all states, health insurers would find it deeply unpopular and politically dangerous.

Genetic discrimination also seems unlikely in employment decisions. For many traits genetic tests are not going to add to information an employer can already get about an employee or job applicant. Any speculative genetic evidence of predisposition to intelligence, good judgment, dedication, and punctuality would pale

"Some people who are currently covered through employers will lose that coverage either by job changes, changes in family status, or an employer's decision to drop all coverage. And some people currently covered by Medicaid will, by increasing income or assets or by changes in their status, lose that coverage. But it is equally certain that some people who do not now have employer-provided coverage will get it.

'. Siw Mark A. Hall \& Steven S. Rich, Laws Restricting Health Insurers' Use of Genetic Iuformatwon: Impact on Genetic Discrimination, 66 Alr. J. HuM. GENETICS 293 (2000) (finding that "there are almost no well-documented cases of health insurers either asking for or using presymptomatic genetic test results in their underwriting decision"). 
in comparison to better evidence of those characteristics acquired through direct observation. Why test genes when you can directly test for or observe the relevant traits? Predictive tests also lose power because of employee turnover. Imagine a job applicant with a predisposition to a fatal condition. At the time of hiring, the predisposition can be detected by genetic test even if the applicant presents no symptoms. If the likely onset of serious symptoms is ten years away, the employer has to discount those future costs, not just because they are in the future, but because of the high chance the applicant will have changed jobs. (And, depending on the firm's pension program, any remaining costs might be outweighed by the savings on retirement benefits.)

There are two more realistic concerns about employment discrimination. The first is the cost of health benefits. The employment-related health coverage for those 150 million people is not free; employers pay the bulk of it, albeit with the help of substantial federal and state tax subsidies. For most employers, employees with more health problems lead to higher health benefit bills; for the many employers, including most large employers, who self-insure, those costs are felt almost immediately. Some, including an earlier version of myself, ${ }^{13}$ have argued that these health care costs would provide a strong financial incentive for employers to avoid hiring or retaining people with genetically predictably high health costs. There is no sign that this has happened-well-documented examples of genetic discrimination in employment are as rare as they are in health coverage. Given the rarity of powerful disease genes, the weaknesses of common disease genes, the speed of employee turnover, and the vast number of other causes of health costs, I now believe that the financial incentives for such discrimination will only be significant in uncommon cases like Huntington disease.

The second concern revolves around health and safety risks to either the employee or to others. A few people have genetic variations that make exposure to particular conditions or chemicals dangerous. This kind of currently uncommon knowledge of occupational exposure risk could lead employers to attempt to select out susceptible workers rather than provide uniformly safe workplaces. The genetic argument can also be made about the safety of third parties. One might argue that a person with a Huntington disease

${ }^{13}$ Henry T. Greely, Health Insurance, Employment Discrimination, and the Genetics Revolution, in THE CODE OF CODES: SCIENTIFIC AND SOCIAL ISSUES IN THE HUMAN GENOME PROJECT (Daniel J. Kevles \& Leroy Hood eds., 1992). 
allele should not become an aircraft pilot or a bus driver, because of the loss of motor control that comes with the disease. This argument will usually founder on the possibilities for continued testing for the actual traits. A pilot who will get Huntington disease could be tested regularly for motor control and could be relieved of flying duties when problems arise. There may be a few cases where the onset is so sudden that such testing for the trait would not suffice. ${ }^{\text {lf }}$ Some employers might have an incentive to discriminate against people at high genetic risk for such a condition, but the genetic variation would have to be highly predictive and the condition's onset unforeseeable, both rare situations.

\section{PRoBlems WTTH REGULATING GENETIC Discrimination}

Whatever the likely present and future scope of genetic discrimination, commentators, politicians, and legislators have been busy calling for its regulation. In doing so, they have made a wide variety of mistakes. Figuring out why and how to push for regulation of genetic discrimination is best begun by examining what not to do.

\section{A. Weaknesses in the Justifications}

The previous Part should have cast doubt on one reason asserted for the regulation of genetic discrimination. Failure to ban such discrimination will not make the sky fall, the employment markets crumble, or hasten a Brave New World of genetic castes. ${ }^{15}$ Most genetic variations will just not be that powerful; most forms of employment and insurance are just not that sensitive.

"A genetically linked condition called Long QT syndrome might be an example. It is associated with sudden death from heart attacks in middle age, often with little or no warning.

"Si grnerally ALDOUS HUXLEY, BRAVE NEW WORLD (1932). Brave New World actually portrays a caste system sustained by a more complicated technology than is commonly remembered. People are born, inside artificial wombs, as clones of up to ninety-six individuals through the forced budding mechanism of the "Bokonorsky Process." Those clones, however, are each produced from a separate fertilized egg. The oraries that produce the eggs and the sperm that fertilizes them are from selected individuals, but the eggs and the sperm are not themselves selected; the resulting zygotes (and clones) are a large set of identical "twins" created by the random sexual mixing of alleles. The different castes are not just the result of the selection of the "parents" of particular clones, but of pre- and post-natal training and conditioning, including the use of oxygen starvation and alcohol poisoning before birth to stunt the Delta and Epsilon castes. (In the context of this Counterpoint, it is ironic that an earlier novel by Huxley was called Point/Counterpoint.) 
But another reason creeps into the argument with the very term used: genetic "discrimination." The Civil Rights revolution, and the subsequent flourishing of movements seeking equal rights, variously defined, for women, the disabled, and gays and lesbians, have made "discrimination" into a bad word, connoting some evil intent. The "discriminating shopper" is not a phrase often heard anymore because the adjective raises images not of careful choices based on the quality of goods being sold, but of immoral choices based on irrelevant personal qualities of the seller. To label something "discrimination" is, today, half the political battle in regulating it.

Of course, people discriminate constantly, in ways that usually have no moral weight. People discriminate in choosing life partners, living quarters, and law schools. Several decades ago, the "bad" discrimination was commonly talked about, at least in legal circles, as "invidious" discrimination, but the "invidious" has become much less common. $^{16}$ The Supreme Court's equal protection jurisprudence provides some insight into what makes us worry about certain grounds for choices when the Court looks more closely at choices based on "suspect classifications" or on "fundamental interests." These two concepts are useful in thinking about claims of rights, whether those claims are made to the judiciary under the Federal Equal Protection Clause or are made politically to legislatures. Discrimination is unfair if it is based on a type of difference that should not be taken into account-disabled status is a statutory example-or if it involves something of great importance-public primary and secondary education could be another legislative example.

Our society's failure to guarantee health coverage or employment makes the "fundamental interest" argument difficult. But calling decisions made on the basis of genetic variations "discrimination" comes easily because such variations share some of the characteristics of other grounds that our society has concluded are improper discrimination. Like race, sex, national origin, and illegitimacy, they are neither voluntarily chosen by their bearer nor readily changeable by that bearer. Like those characteristics and religion, they have been the asserted basis for oppression and stigmatization in the past-about 60,000 Americans were compulsorily sterilized in the twentieth

${ }^{16}$ A search of the Lexis "genfed" library shows the term "invidious discrimination" appeared in $11.6 \%$ of federal cases from 1966 through 1970 where the word "discrimination" appeared, $6.0 \%$ of the cases from 1976 through $1980,3.1 \%$ of the cases from 1986 through 1990 , and only $2.0 \%$ of the cases from 1996 through 2000 573 cases out of over 28,000 . The term seems to be dying out. 
century's eugenics movement. And, like many of those traits, they can be argued to be part of a person's essence, something that should not have to be denied. Should genetic variations be treated as constitutional "suspect classifications," like race, sex, national origin, or their statutory equivalents, disability, old age, or sexual preference? The resemblances are tempting but, I believe, both superficial and dangerous.

The resemblances are superficial because they confuse a person's genotype with its expression. A person's genome is unchosen ${ }^{17}$ and, at present at least, not susceptible to intentional change. ${ }^{18}$ Even if these are morally critical points, ${ }^{19}$ genetic variations affect people only as they are expressed and, as detailed above, the same genetic variations can express themselves quite differently, as a result of treatment, environment, or chance. A child does not choose PKU. But the child's parents can choose to avoid the mental retardation that follows untreated PKU. Similarly, the history of oppression based on genetics is one of oppression based on expressed traits-feeblemindedness, criminality, slovenliness-that were thought, largely incorrectly, to have a genetic basis. Although the concept of recessive disorders, central to Mendel's discovery of the underlying rules of genetics, was well known during the eugenics period, people who were only carriers of recessive genes were not sterilized. Only people who actually expressed the traits were sterilized. The gap between the genetic variations as they exist and the way in which they are expressed in the whole person also argues against the idea that "Genes 'R' Us," in other words, that our genes are our essence.

That a person carries one copy of the genetic variation that, when present in two copies, usually produces cystic fibrosis should not be viewed as the same as that person's race, sex, national origin, religion, or sexual preference. For better or for worse, the latter characteristics have great significance, at least in our culture. The unexpressed

17 There are people alive, almost all still children, whose parents chose to continue their gestation after examining one or more genetic sites through prenatal testing or, more recently, prenatal genetic diagnosis. Even aside from the limited extent of such choice, limited both in the number of genes examined and in the number of people affected, the choice was the parents', not the person's.

is The successful clinical use of gene therapy could make a person's genes "changeable," but only' a small number of genes and usually only in a few special types of cells.

"Mere nonvoluntariness or immutability should not confer, by themselves, special status. We do not voluntarily choose our birthdays or our social security numbers and cannot (readily) change either. 
genotype has no such significance. And although the expressed genotype might have similar significance-or might even correlate strongly with a person's race, sex, or religion-the validity of discrimination based on that trait should be evaluated on the expressed trait, not on whether or not it has a genetic origin. Whether a person with cancer should be subject to discrimination should be evaluated based on the social significance and consequences of cancer, not on whether her particular case of cancer was or was not associated with an inherited genetic variation.

Promoting genetic variations to suspect status, either constitutionally or through giving them special legislative significance, is not only inappropriate but potentially damaging. By telling people that their genetic variations are so important-are the equivalents of race, sex, religion, and other suspect classifications-we encourage them to believe that it is true, in ways that are both inaccurate and pernicious. $^{20}$

This is not to say that using genetic traits as a basis for discrimination is free from moral question. If the trait is irrelevant to the decision at hand, it could still be disapproved of as arbitrary and hence, to some extent, immoral. ${ }^{21}$ But as a general matter we allow wide scope for private citizens and private businesses to act arbitrarily and capriciously in whom they hire, fire, or serve-as long as they do not act on the basis of specified impermissible criteria. ${ }^{22}$ For a private firm to use a completely irrelevant genetic variation as a grounds for making employment or insurance decisions might be condemnably arbitrary but would seem a slim argument for legislative intervention.

\section{B. Definitional Dilemmas}

Statutes and proposed statutes regulating "genetic discrimination" typically forbid someone, usually an employer or health insurer, from taking action based on "genetic information," "genetic

${ }^{20}$ See the further discussion of this point infra Part II.C.

${ }^{21}$ Of course, irrelevant and purposefully arbitrary distinctions may be useful, such as randomly drawing names for a jury venire or flipping a coin (or playing a hand of poker) to resolve a tied election. See Henry T. Greely, The Equality of Allocation by Lot, 12 HARV. C.R.-C.L. L. REV. 113 (1977).

${ }_{22} \mathrm{Or}$, in the case of a business, do not withhold an essential service. Common carrier requirements are historical remnants of the second concern. The Emergency Medical Treatment and Active Labor Act, 42 U.S.C. $\$ 1395$ dd (1994), which effectively' requires hospitals to provide care to all patients with emergency conditions, is a modern example. 
characteristics," or the results of "genetic tests." What do those terms mean? Existing statutes generally use one of two approaches-one narrow, one broad, both seriously flawed.

The narrow definition bans the use of the results of "genetic tests" and defines those genetic tests as tests of "DNA." The Wisconsin statute provides an example of such a definition, now used in relatively few states:

(1) In this section, "genetic test" means a test using deoxyribonucleic acid extracted from an individual's cells in order to determine the presence of a genetic disease or disorder or the individual's predisposition for a particular genetic disease or disorder. ${ }^{23}$

This has the advantage of being relatively clear, but the disadvantage of being easy to circumvent, intentionally or not. Genetic information can come from many sources other than DNA tests. Tests for carrier status of Tay-Sachs disease, sickle-cell anemia, and APOE status, for example, have all been routinely done, in the past or in the present, on proteins, not on DNA. The genetic variations involved in these conditions lead the body to produce slightly different proteins, which can be separated out and tested for without dealing with DNA. Those "genetic tests," and others, are routinely done without using any DNA. Someone who wanted to circumvent a narrow statute could also do DNA-based tests by looking not at the DNA itself but at RNA, produced from the DNA template. The DNA necessarily defines a particular RNA sequence, which, when read, can provide full information about the DNA sequence that coded for it.

Many statutes now take into account these broader ways of testing for genetic variations. Michigan's statute provides a good example:

(b) "Genetic information" means information about a gene, gene product, or inherited characteristic derived from a genetic test.

(c) "Genetic test" means the analysis of human DNA, RNA, chromosomes, and those proteins and metabolites used to detect heritable or somatic disease-related genotypes or karyotypes for clinical purposes. A genetic test must be generally accepted in the scientific and medical communities as being specifically determinative for the presence, absence, or mutation of a gene or chromosome in order to qualify under this definition. ${ }^{2 *}$

This broader version of the narrow definition fails in an even

"IICH. COMP. LAW'S ANN. $\$ 550.1401$ (West 2000). 
more important way. Some "genetic information" can be obtained without doing any tests for the purpose of identifying genetic variations. A family practitioner, on seeing a twenty-five-year-old patient with a cholesterol level of 650 , should suspect the genetic disorder, familial hypercholesteremia. ${ }^{25}$ A pediatrician can, with great accuracy, diagnose whether a child has the chromosomal disorder Down syndrome without doing any biochemical tests, through the child's appearance and, later, behavior. And any of us, on very little inspection, can make a very good, albeit not perfect, guess as to whether a person carries a copy of the SRY gene, and is male, or does not, and is female. Similarly, the family history that is part of any good physician's examination reveals some probabilistic genetic information. ${ }^{26}$ A person with a parent who died of Huntington disease has a fifty percent chance of carrying the Huntington allele. A person with three or four close relatives, on the same side of her family, who had early-onset breast or ovarian cancer has a much higher than average chance of carrying a mutated BRCA 1 or BRCA 2 gene. A narrow definition of genetic discrimination, based on the results of genetic tests, misses all these sources of genetic information.

This is not a novel insight. A group assembled by the National Human Genome Research Institute of the National Institutes of Health early on recommended a broad definition of genetic information, which has been adopted by numerous states. ${ }^{27}$ A typical broad statute forbids discrimination based on genetic information, defined:

(2) "Genetic information" means information about inherited genes or chromosomes, and of alterations thereof, whether obtained from an

${ }^{25}$ Some of the "genetic test" definitions deal with the genetic implications of biochemical tests that were not done for the purpose of finding genetic information by expressly excluding them from the definition. For example, the Minnesota statute provides that "'genetic test' does not include a cholesterol test or other test not conducted for the purpose of determining the presence or absence of a person's gene or genes." MINN. STAT. ANN. \$ 72A.139(2)(b) (West 1999). The Texas statute says that genetic tests do not include: " $(A)$ a routine physical examination or a routine test performed as a part of a physical examination; (B) chemical, blood, or urine analysis; (C) test to determine drug use; or (D) test for the presence of the human immunodeficiency virus." TEX. INS. CODE ANN. \$21.73 (Vernon 2000).

${ }^{26}$ The Oklahoma statute expressly excludes family history: "'Genetic information' means information derived from the results of a genetic test. Genetic information shall not include family history...." OKLA. STAT. ANN. tit. 36, \$ 3614.1.B.3 (West 1999).

${ }^{27}$ See Kathy L. Hudson et al., Genetic Discrimination and Health Insurance: An Urgent Need for Reform, 270 SCIENCE 391 (1995); Karen H. Rothenberg, Genetic Information and Health Insurance: State Legislative Approaches, 23 J.L. MED. \& ETHICs 312 (1995). 
individual or family member, that is scientifically or medically believed to predispose an individual to disease, disorder or syndrome, or believed to he associated with a statistically significant increased risk of development of a disease, disorder or syndrome. ${ }^{28}$

The broad approach has its own set of problems, stemming from an unintended "feedback effect." If a person has been diagnosed with Huntington disease, that provides certain genetic information-that person must carry at least one mutated allele of the gene that causes the disease. If a person has been diagnosed with sickle-cell anemia, that is conclusive evidence that she carries two copies of a gene with the particular sickle-cell mutations. If this medical information is treated as genetic information because it yields inferences about genes, the broad definition effectively outlaws all consideration of medical conditions that have some probabilistic association with inherited genetic variations.

Careful delineation is important in another respect. A legislature needs to consider carefully the scope of limitations on the use of genetic information it wants to impose. Not all users raise the same issue, nor do all uses. Laws banning the use of genetic information in "insurance" could be overly broad. Life insurance is not the same as health insurance. A standard, low-benefit whole life insurance policy is not the same as a high-benefit term life insurance policy. Disability insurers or long term care insurers may similarly have legitimate reasons to worry that people who know that their genetic variations put them at high risk will disproportionately buy that insurance (socalled "adverse selection"). In the United States, health coverage of some sort should be riewed as a necessity; life insurance, disability insurance, or long term care insurance seem less compelling. In all other rich countries, health insurance is universal and genetic discrimination has little importance in that context. On the other hand, in the United Kingdom, borrowers, for mortgages or even automobile loans, often have to get individually underwritten credit life insurance. For them, genetic discrimination in life insurance may have a much greater negative affect than genetic discrimination in privately sold health insurance. Insurance for long term care, a newly created and still struggling insurance line, might be killed by adverse selection from people who knew they were at genetically higher risk for Alzheimer disease. A public policy in favor of promoting such insurance might argue against banning genetic discrimination for it.

$\therefore$ DEL. CODE ANN. tit. 18, $\$ 2317(a)(2)(2000)$. 


\section{The Problem of Politics}

The biggest problem in regulating genetic discrimination is not the method of regulation but the campaign to obtain it. Advocates of regulating genetic discrimination will be tempted to build support by exaggerating the importance of the problem. In so doing, they may make the cure worse than the disease.

The problem can be exaggerated first by scaring people about the likely significance of current and future genetic discoveries. If people are convinced that human genetics research will lead to the discovery of strong genetic associations for most diseases-like the perfect association between genetic variations and diagnosis (and inevitable death) from Huntington disease-protection from discrimination will seem more important. Ignoring the many structural limitations on, for example, the use of medical underwriting in health insurance will further help make the case for antidiscrimination legislation. Pointing out the important use of rare genetic associations to find mechanisms of disease and targets for preventive or therapeutic intervention, though accurate, will not obviously build support for such legislation. Scaring people about their own risk of genetic discrimination will.

Similarly, the association of a person's genotype with her "essence" increases the perceived importance of protecting that essence and preventing discrimination based on it. Perhaps the best example is George Annas's use of the metaphor of an individual's genome as her "future diary." A diary-secret, important, uniquely individual-is a powerful metaphor for building political support. But it is almost completely inaccurate. For most people their genetic risks will be a relatively small contributor to the overall risks of life, just one component to be added to environment and chance. The fact that no two genomes are identical (apart from those of identical twins) does make them unique, but our fingerprints are even more uniquely our own (identical twins have different prints) without justifying careful protection. Stressing the deeply personal, unique, and important nature of an individual's genotype may build political support, but at a cost to accurate public understanding of the real significance of genetic variation and human genetics research.

Unhappily, efforts to "hype" the dangers of genetic discrimination or the importance of an individual's genome find an environment

${ }^{29}$ George J. Annas, Privacy Rules for DNA Databanks: Protecting Coded Future Dianes, ' 270 JAMA 2346, 2346 (1993). 
receptive to such exaggeration. Biotechnology firms, living and dying by, or in the shadow of, the stock markets, have a real financial interest in convincing the public of the crucial importance of genes, particularly the genes they are studying. Researchers, seeking jobs, grants, tenure, and glory, also have incentives to exaggerate the importance of their work. More innocently, any researcher (even a law professor) likes to believe that what she does is important-this ubiquitous incentive to perceive one's work as important must play some role in the hyping of the genome. Even politicians get into the act. The joint press conference of President Clinton and Prime Minister Blair announcing the "completion" of the sequencing of the human genome was not short on hyperbole. And, of course, all of these incentives to stress the crucial nature of human genetics and the human genome are covered by the various communications media, which also have an interest in stressing the importance of what they cover.

Exaggerating the importance of human genetic variations has important costs. First, it makes the public more frightened of genetic research and its possible implications. If this were to reduce popular or political support for such research, the alleviation of much human suffering might be delayed or stopped entirely. Second, it increases the extent to which people see their lives as controlled by their genes, a process Susan Wolf has termed "geneticism.", James Watson was once quoted as saying, "We used to think our fate was in our stars. Now we know ... our fate is in our genes." "31 To the extent people believe this is true, our culture will change in ways that are both scientifically unsound and socially pernicious. The fight between "nature" and "nurture" is a long one..$^{32}$ Clearly, the science of genetics has helped move the conventional wisdom on that question toward nature from the nearly exclusive emphasis in the 1960s on nurture. But it should not be allowed to move the balance too far. The only plausible answer to the question of "nature or nurture," for most people, most of the time, is "yes." Both play a crucial role. Exaggerating the importance of genetics, even for the "good cause" of passing legislation against genetic discrimination, may well do more harm than good.

"Susan Wolf, Bejond "Genetic Discrimination": Toward the Broader Harm of Gi'utirism, 23 J.L. MED. \& ETHICs 345, 346 (1995).

'I Leon Jaroff, The Gene Hunt, TiMe, Mar. 20, 1989, at 62, 65.

'z Se' gentrally CaRL N. Degler, IN SEARCh OF HuMan NaTURE (1991). 


\section{THE CASE FOR CAREFUL REGULATION OF GENOTYPE DISCRIMINATION}

So far, I have discussed the weaknesses in many calls for the regulation of genetic discrimination, perhaps confusing some readers as to whether this piece was the "point" or the "counterpoint." But there is a strong case for some carefully argued and crafted limitations on discrimination in employment and health insurance based on an individual's genotype. This Part lays out first the "why" and then the "how" of that case.

There are three good reasons for federal regulation of some kinds of genetic discrimination: to protect those few people whose unlucky genetic inheritance puts them at risk for rational discrimination, to protect those people who are at risk for irrational and ill-informed genetic discrimination, and, most importantly, to allay public fears that could impede important genetic research.

The science of human genetics is showing us that a small percentage of people carry inherited genetic variations that put them at high risk for serious illness. About 1 person in 20,000 carries a Huntington disease allele, perhaps one person in a thousand carries a mutated gene that will almost certainly lead to Alzheimer disease, and maybe 1 or 2 women in 1000 carry mutated genes that move their risk of getting breast cancer from about $10 \%$ to somewhere from $50 \%$ to $85 \%$. An insurer or employer might well rationally decide to discriminate against those people if they receive their health insurance or are in an employment market in which such discrimination is even possible. The vast majority of us carry genetic variations that put us at higher- or lower-than-average risk for particular diseases, but not greatly higher or lower risks-and not different enough to prompt rational discrimination.

Still, those people who are at risk should be protected. Both employment and health insurance are important parts of life in contemporary America. The Americans with Disabilities Act ("ADA") and equivalent state laws provide some employment protection for people who suffer from disabling diseases. We can afford to provide both employment and health insurance protection to those few people whose genetic variations yield a firm prediction that they will suffer from such diseases. Preventing such discrimination against a small number of people, at least if done through carefully drawn legislation, should have only minor costs to the economy but major benefits for those few people whose jobs or health insurance would be saved. 
Second, everyone is at some risk for irrational genetic discrimination. As I was finishing this Counterpoint, I read a newspaper report of a complaint filed by the Equal Employment Opportunity Commission ("EEOC") against Burlington Northern Corporation." According to the report, the railroad had been subjecting employees with carpal tunnel syndrome to a genetic test, looking for genetic variations that were linked to susceptibility to the syndrome. ${ }^{3 / 4}$ There is no good reason to expect those employees to have that genetic condition. ${ }^{35}$ But someone, somewhere in Burlington Northern's corporate structure somehow decided this testing, done without informed consent, was a good idea. A general ban against the use of genotypes in employment would prevent, or at least deter, a wide range of possible stupid genetic discrimination.

Finally, and most importantly, clear federal legislation could address fears about genetic discrimination. Whether those fears are justified or not, they exist. And people who are afraid of genetic discrimination are afraid to take genetic tests that offer the possibility of improving their health. They may be afraid to take part in genetic research that could provide important answers to major diseases and they may not be willing to provide political support for genetic research. If one believes, as I do, that research in human genetics has enormous potential for alleviating human suffering, reducing this fear is important. Having one law, across all states, that clearly prohibits discrimination on the basis of genotype should go some way to reducing fear. According to an excellent recent study, genetic counselors typically tell patients that genetic discrimination is covered

"Lisa Girion, Nurse Derails Genetic Testing: Wife of Railroad W'orker Sparks Probe That May Have Wide Implications, L.A. TMES, Feb. 25, 2001, at W1.

it Id.

There does appear to be some evidence that many people with a particular rare genetic condition have, as one of the condition's many symptoms, a propensity to carpal tunnel syndrome. The railroad seems to have been testing for this condition, called Hereditary Neuropathy with Liability to Pressure Palsies ("HNPP"). HNPP is found in about 2 to 5 people out of 100,000 -thus, it would be expected to be found in 5,000 to 15,000 people in the entire United States. The first attack usually occurs in the patient's teens or twenties. Thomas D. Bird, Hereditary Neuropathy with Liability To Pressurt Palsites Gene Clinics, (June 15, 2000), http://www.geneclinics.org/profiles/ hnpp. It seems likely that someone within the company not only ignored these facts, but also made the unjustified jump to concluding that a significant fraction of people with carpal tunnel syndrome had that genetic condition. Even with that misunderstanding, it remains unclear why exactly the railroad was testing people who already had symptoms; their symptoms alone would be enough, with or without any hypothetical genetic predisposition, to modify their duties and working environment. 
by a patchwork of inconsistent state laws, all of which have loopholes. One well-written and uniform federal statute could provide reassurance for those who fear genetic discrimination.

Of course, such reassurance will certainly not be universally effective. One might argue that a similar result could be reached by educating people away from their largely unrealistic fears of such discrimination, but it is hard to believe that such an education campaign would be more effective than a statute. The costs of welldrafted antidiscrimination legislation are low. The potential benefits from reducing public fear, though necessarily hard to quantify, seem to me to justify such legislation, particularly when added to the relief from real discrimination such a statute would bring to those few people at risk for rational discrimination and the many at risk for irrational discrimination.

Federal regulation, as noted above, seems likely to be most effective in reducing public fears of genetic discrimination. It also can reach self-insured employee health plans, which, under the Employee Retirement Income Security Act of 1974, are largely free from state regulation (although some states have tried to ban genetic discrimination in such plans). ${ }^{37}$ Federal legislation has the further advantage that good legislative language need be crafted, and a good political campaign mounted, only once. ${ }^{38}$ Such federal legislation needs to have three important substantive characteristics: a careful definition of the information whose use constitutes discrimination, a structure for dealing with many of the ancillary issues that will necessarily arise, and an appropriately limited scope.

The definition of genetic discrimination should regulate the use of information about a person's genotype, or genetic variations, however obtained or inferred, but should not add any new regulations to the use of information about a person's phenotype or actual expressed characteristics. Genetic information should thus be defined very broadly to encompass any other information that provides probabilistic information about a person's genotype. This information can come from genetic tests, other medical tests, family

${ }^{36}$ Mark A. Hall \& Stephen S. Rich, Genetic Privacy Laus and Patients' Fear of Discrimination by Health Insurers: The View from Genetic Counselors, 28 J.L. MED. \& ETHICS 245 (2000).

${ }^{37}$ See, e.g., CAL. INS. CODE $§ 10123.3$ (West Supp. 2001).

${ }^{33}$ It is possible, of course, that a state might choose to impose greater restrictions on the use of genotype discrimination than the federal statute, but that seems unlikely if the federal statute is reasonable. 
history, diagnoses of traits or conditions, or the taking of (or even making inquiries about) a genetic test. The information could come directly from the individual involved or from a relative. ${ }^{39}$

The broad sweep of this definition of genetic information is only feasible, however, if the definition expressly excludes decisions made on the individual's phenotype. Otherwise, employers and insurers could reasonably fear that a person with Huntington disease or early onset Alzheimer disease could sue for genetic discrimination on the ground that her condition provided evidence about her genotype. The way to make this distinction is conceptually straightforward, though perhaps complicated to implement. The definition should not cover the use of any information about the individual's own physical condition or medical symptoms; use of that information should be permitted to the extent allowed by other laws (such as the $A D A)$. For example, a health insurer could not use information that the individual carried a thus far unexpressed genetic susceptibility or predisposition to a disease, whether or not that information came from a genetic test, a physical examination, or the expressed symptoms of family members. It could use, to the extent currently permitted, information about an individual's medical condition, even though that condition gave strong evidence about the person's genotype. This combination means that the statute would forbid actions based on the individual's genotype, regardless of how information about that genotype was derived, but would not affect actions based on the individual's phenotype. "There could, of course,

A sibling's genetic test results provide some probabilistic information about an individual's genotypes; a pregnant woman's request that her fetus be tested for an uncommon genetic condition provides some probabilistic information about both her genotype and her mate's.

Some existing statutes proxide for something similar to this exclusion. For example, California's ban on genetic discrimination in health coverage bars the use of genetic characteristics, defined as:

(I) Any scientifically or medically identifiable gene or chromosome, or combination or alteration thereof, that is known to be a cause of a disease or disorder in a person or his or her offspring, or that is determined to be associated with a statistically increased risk of development of a disease or disorder, and that is presently not associated with any symptoms of any disease or disurder.

(2) Inherited characteristics that may derive from the individual or family member, that are known to be a cause of a disease or disorder in a person or his or her offspring, or that are determined to be associated with a statistically increased risk of development of a disease or disorder, and that are presently not associat'd with any symptoms of any disease or disorder.

C.AL. HEILTH \& SAFETY CODE $\$ 1374.7$ (d) (West 2000) (emphasis added). The 
always be some arguments about whether a physiological change in the phenotype, such as an unusual form of a protein, was information about physical condition or a medical symptom. The statute could address that problem by limiting the use of phenotypic characteristics in insurance and employment to those that are "medically significant symptoms."

A well-crafted statute will also need a structure to deal with ancillary issues. At least with respect to employment, the ADA might provide a useful structure. For example, a public health and safety exception might be thought useful. It could be that some genetic predispositions could greatly increase the risk of sudden death, which might be dangerous in an airline pilot (or a bus driver). The ADA's health and safety exception could handle those issues. Similarly, in a case in which an employer were to claim that an employee's genotype created special susceptibility to workplace exposures, the ADA's framework could be used to ask whether the employee could perform the job functions with a reasonable accommodation that did not impose an undue burden on the employer. Finally, the ADA's enforcement mechanisms, both through the EEOC and through the courts, could be used for this statute.

The third substantive issue concerns the scope of regulation of genotype discrimination. I believe that, at present, it should be limited to employment questions and to health coverage (whether through traditional health insurance, HMOs, or a self-funded employee health benefit plan). To the extent that genetic information allows the confident prediction of future health, that information might be used in other insurance contexts-life insurance, disability insurance, and long-term-care insurance-or in noninsurance matters-such as whether to admit someone to medical school or allow her to become an adoptive parent. Each possible use raises its own set of questions. Currently, in the United States at least, health coverage and employment seem to be the issues of most general importance and the issues of greatest public concern. Congress should limit federal legislation to those two areas at this time and give an agency the responsibility for studying and reporting to

reference to "presently not associated with any symptoms of any disease or disorder" encompasses some of the ideas discussed in text, although it is somewhat vague (associated with any symptoms in whom?). This statute excludes any characteristics that are presently associated with symptoms from the definition of genetic characteristics; it would be better to include information about an individual's genotype derived from his symptoms in the category of genetic information but to allow it to be the basis for employer or insurer decisions. 
Congress on possible extensions of the genotype discrimination statute to other fields.

Finally, federal genotype discrimination legislation needs to be more than substantively careful. It needs to be pursued in a way that does not cause undue anxiety-or encourage undue genetic determinism. Dictating the substance of legislation is difficult enough; for an academic to prescribe the political process through which it should be adopted may be delusional. But it would be best if this legislation could be passed without a major political campaign, preferably with the advance agreement of the affected business and consumer constituencies. Surprisingly, this may not be that difficult to reach. Employers, though loath to accept any new limitations on employment discrimination, should prefer a uniform and carefully drawn federal rule to a variety of state laws. The major health insurers and HMOs do the bulk of their business through employer-provided plans that do not medically underwrite. That business would not be affected by this legislation. Only the small, medically underwritten health insurance market would be affected and it is already dealing with less clear legislation in almost every state. The very fact of the passage of so much state legislation is some evidence that the major political interests affected by it can live with it. An agreement on federal legislation that would avoid an inflammatory, and quite likely misleading, political fight may well be possible, perhaps brokered by the pharmaceutical and biotechnology industries that hope to profit most directly by the genetics revolution.

\section{CONCLUSION}

This argument in favor of laws regulating genetic discrimination started by addressing all the weaknesses in the case. This Counterpoint illustrates some dangers of the Point/Counterpoint format. The human genome and its workings are nearly as complicated as human societies and their workings-neither benefits from overzealous expression. 
* $\quad * \quad * \quad * \quad * \quad *$ 